\title{
The Effect of Stress and Work Overload on Employee's Performance: A Case Study of Public Sector Universities of Khyber Pakhtunkhwa
}

\author{
Fahad Ikram Ul Haq, Aftab Alam, Syed Sardar Ul Mulk, and Farah Rafiq
}

\begin{abstract}
The purpose of this research was to study the effect of stress and work overload on employee's performance of various public sector universities of Khyber Pakhtunkhwa. For this study, the province of Khyber Pakhtunkhwa was selected firstly and five (05) different public sector universities were designated for the analysis. The study was quantitative and for this purpose. The collected data was analyzed with the help of statistical package for social sciences (SPSS). Using Correlation Analysis the relation between the variables was found which illustrated that both the independent variables (Stress and Work Overload) were negatively related to the dependent variable (Employee's Performance). The Regression analysis tool was used to check the effect of both independent variables (Stress and Work Overload) on the dependent variable (Employee's Performance). The results gave clear evidence that if the employees are stress due to any reason either internal or external and are overburdened, uncomfortable in their job, their performance towards the organization will be low which ultimately will make hurdles in achieving organizational objectives.
\end{abstract}

Index Term - Work Overload, Employee's Performance, Role Conflict, Job Insecurity, Occupational Challenges, Motivation, Job Satisfaction.

\section{INTRODUCTION}

This research examines Stress and Work Overload on Employee's Performance in public sector universities of Khyber Pakhtunkhwa. Amongst the maximum disturbing of these worries is the connection of Stress to the performance of employees working in the said sector. Stress and Work overload have effects on employee's overall productivity in many negative ways which in turn can have an impact on the overall organization performance and hence can be a big hurdle for the organization for achieving any competitive

Advantage and achieving its long term strategic goals.

The factors that challenge stressors are the demand for

Published on January 8,2020

Fahad Ikram Ul Haq, Department of Management Sciences Abasyn University Peshawar Pakistan.

(e-mail: fahad_ikram@ymail.com)

Aftab Alam, Department of Management Sciences Abasyn University Peshawar Pakistan.

(e-mail: aftabalam112@gmail.com)

Syed Sardar Ul Mulk, Department of Management Sciences Abasyn

University Peshawar Pakistan.

( e-mail: syedsardar@awkum.edu.pk)

Farah Rafiq, Department of Management Sciences Abasyn University Peshawar Pakistan.

(e-mail: farahrafiq002@gmail.com) doing the more, scope of work and responsibility. The issues regard to hinder stressors are role ambiguity, organizational politics, and job insecurity (Sonnentag \&Fritz, 2015).

It is very important for the organization to consider the employee's satisfaction level if they would want to provide high-quality services/products. This is because satisfied

Employees are productive (Garton\& Mankins, 2015).

The purpose of my study is to find out how stress and work overload affects employee's performance in public sector universities of Khyber Pakhtunkhwa. The focus of the study is to discover the relationship between stress and work overload with the employee's performance. This study is now mandatory because stress and work overload is a critical problem of organizations of today. This problem promotes stress and work-life conflict and demotivates employees which tend to decrease in the performance and employee involvement in their job.

The area of this research is the public sector universities of Khyber Pakhtunkhwa. As incentive is the best way to motivate employees (Kvaløy\& Schöttner, 2015), due to the vast number of universities the focus will be on some selected universities where employees (faculty and administrative employees) are involved in additional tasks but no incentives are paid to their workers for extra work. Secondly, most employees belong to some political background and affiliation with the reporting officers due to which they even don't have the interest to come for a job. This reason ultimately results in extra workload on some employees and leads to low job satisfaction. The other factor is the stress which is facing by the employees of these institutions due to job insecurity, having a threat from some forums or due to some other external

\section{Problem Statement}

The writings and various revisions shed light arranged the impact of Stress and Work overload on the enactment of employees of the organizations. These organizations are banking sector, pharmaceutical, investment or some particular organization. Stress can be either positive or negative for employees subjected to their level. If there is no stress, it restricts occupational challenges and the abilities of 
employees become low because the performance of employees decreases with an increase in stress (Baron et al., 2016).

The emphasis of our present revision is that's why to discover the impact of stress that is imposed on the employees working in Public organization particularly. The other emphasis is to analyze the performance of these employees or group of employees when we put extra work on them. In the study, the pubic organizations are the public sector universities of Khyber Pakhtunkhwa.

\section{RESEARCH QUESTIONS}

-Is there any effect of stress on employee's performance? -Is there any effect of work overload on employee's Performance?

\section{RESEARCH OBJECTIVES}

- To observe the consequence of Stress on Employee Performance.

-To scrutinize the outcome of work overload on Employee Performance

\section{Literature REVIEW}

\section{Stress}

Stress is generally known as the pattern of troublemaking physiological and psychological reactions to events that threaten the ability to cope. In other words, stress is the body's reactions to changes that create challenging demands. The stress can be either positive or negative. The positive stress is short term and includes the characteristics of being motivated, feeling excited and it improves performance. On the other hand, negative stress is also called distress. It can be short or long term and may include anxiety, feeling unpleasant, decreases performance and can lead to mental problems.

R. Reddy (2008) defined stress as a condition that should make an individual move away commencing ordinary working due to the alteration in his emotional \& physical circumstances. The long-lasting occupation pressure is that which causes the routine \& repetitive path of industry, as a result usually disturbing everyday operational timetable of workers. The motivation which is the guideline for expressive reactions alongside the stress causes should choose the purpose of the incoming of workers (Aguinis et al., 2013). Stress is a fundamental reason for intentional happening in the establishments of causing damage to the labor force (Zhang \&Lee, 2010).

\section{Work Overload}

When some work exceeds the individual's ability to do the assigned job, it creates pressure. It is a condition in which the person feels stress, or when the requirements of the circumstances are much greater than what can be treated. If these circumstances continue for a long time without any interruption, they generate different behavioral, physical and mental problems. It is a tactic normally used by the manager to increase motivation and productivity but sometimes, in the long run, these methods have negative consequences. A study of stress in the USA found that $45 \%$ of the employees complained about work overload. More recently a survey comprised of male upper middle-level manager indicated that work overload was the single most frequently perceived source of job-related stress (Knezevic et al., 2011)

\section{Employee's Performance}

Employee performance is important for any organization and indicates whether the employee is doing well or not. Performance includes the actions of staff in their professions related to the organization's objectives (Schechner, 2013). Additional description of the performance by Prawirosentono,(2008), the work that can be achieved by an individual working or organization group are in agreement with the authority and responsibilities of each in an determination to accomplish with authorization relevant organization goals, not in contradiction of the law and in harmony with moral and ethical standards. Muchinsky, (2003) describes the performance as an arrangement of an employee's behavior in achieving their job results. In addition, it was described that it is possible to measure, evaluate and examine as staff-level outcomes and can be linked with organizational objectives. Therefore, performance is critical to the achievement of the organization.

\section{THEORETICAL FrAMEWORK}

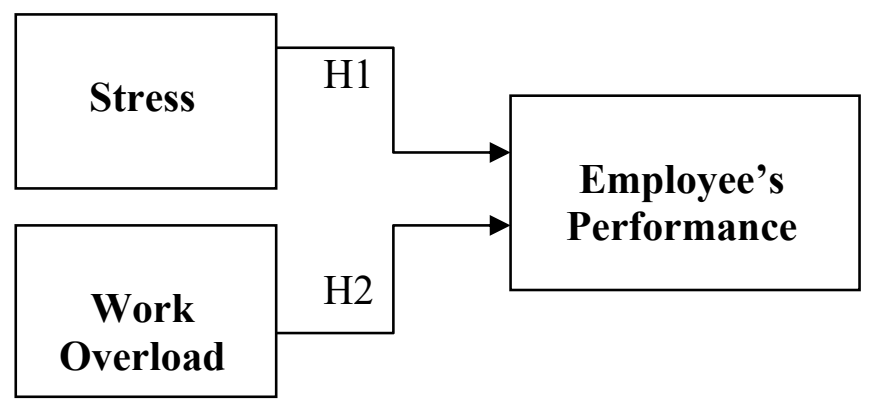

\section{Hypotheses}

H1: There is a significant association between Stress and Employee's performance

$\mathrm{H} 2$ : There is a significant association between works Overload and Employee's performance 


\section{Research Design}

The nature of research is quantitative. The aim of the study is to test the effect of stress and work overload on employee's performance. For this purpose, the questionnaire is the most appropriate method for data collection. An adopted questionnaire of Donald A. Buckingham (2004) and Kavitha Venugobal (2017) is used to collect the data. Each item was measured with a five-point Likert scale. The collected data is then analyzed with the help of statistical package for social sciences (SPSS).

\section{Population}

For analyzing the effect of stress and work overload on employee's performance the focus of the study is public sector universities of Khyber Pakhtunkhwa. There are almost 39 public and private sector universities in the province of Khyber Pakhtunkhwa. The target population for the research is the faculty members and staff of the following institutions:-

1-Women University, Mardan

2-Abdul Wali Khan University, Mardan.

3-University of Engineering and Technology, Mardan.

4-University of Swabi, Anbar.

5-University of Malakand, Chakdara.

There are almost 4000 employees working in the abovementioned institutions. Due to lack of resources, good time management and respond accurately to the questionnaire, employees working from Pay Scale of 15 to 18 were contacted which were almost 1000 employees. The remaining staff/faculty were excluded from the population of the study.

\section{Sample Size and Sample Techniques}

The sample represents a part of the population. Sample from the complete data of all institutions is selected because it is very difficult and time-consuming to take the whole population of the above mentioned institutions to test the hypothesis. For the survey of the study, questionnaires were distributed among the selected employees of said organizations. The sample size is 281 as derived from Yamane formula:

n

$$
=1+\frac{\mathrm{N}}{\left(\mathrm{N} \times \mathrm{e}^{2}\right)}
$$

Where:

$$
\begin{aligned}
& \mathrm{n}=\text { Sample Size } \\
& \mathrm{N}=\text { Population } \\
& \mathrm{e}=\text { Margin of Error }(5 \%) \\
& \mathrm{n}=\text { Sample Size }
\end{aligned}
$$

\section{Measurements and Instrumentation}

The survey strategy of the study had adapted the questionnaire for the collection of data from respondents of the study. Items in the questionnaire are designed on a fivepoint scale i.e. Strongly Disagree, Disagree, Neutral, Agree and Strongly Agree. There are three main sections of the research instrument used in the survey, the Stress, Work overload and Employee Performance section. The first part consists of 06 questions and is designed to collect data from the respondent regarding stress in their organization. The second part consists of 04 questions and is designed to collect data for work overload assigned to them. The third part of the questionnaire collects data about employee performance while having stress and or work overload. This section consists of 05 questions.

\section{DATA ANALYSIS AND RESULTS}

\section{Stress Construct}

This section defines the level of Stress of employees working in the current organization. A lot of researchers have identified various dimensions of Stress that are associated with the employee's performance. All five universities were visited to get the response of employees regarding the stress they are facing while working there.

A six items scale was used to measure the level of stress which was adopted from research study Donald A. Buckingham (2004) and Kavitha Venugobal (2017). The reliability of the questions was analyzed in SPSS and the result shows results as per below

Table 4.1 Reliability of Stress

\begin{tabular}{ll}
\hline \multicolumn{3}{c}{ CRONBACH'S ALPHA } \\
\hline S 1 & 0.865 \\
S 2 & 0.911 \\
S 3 & 0.909 \\
S 4 & 0.945 \\
S 5 & 0.970 \\
S 6 & 0.971
\end{tabular}

The overall reliability of the questionnaire for the current study was found at 0.97

\section{Work Overload Construct}

Different researchers used different instruments to analyze the relationship between work overload and employee performance. But the use of these instruments depends upon the objectives of the study. The instrument used for the current study was adopted from the study of Donald A. Buckingham (2004) and Kavitha Venugobal (2017). Four items were used to examine the effect of work overload on employee's performance. Each question was analyzed using 5 Likert scales, starting from 1 (strongly disagree) to 5 (strongly agree). The Cronbach's alpha shows good reliability of the questions asked regarding work overload

\begin{tabular}{ll}
\multicolumn{3}{c}{ Table 4.2 Reliability of Work Overload } \\
\hline CRONBACH'S ALPHA \\
WL 1 & 0.950 \\
WL 2 & 0.952 \\
WL 3 & 0.829 \\
WL 4 & 0.936 \\
\hline
\end{tabular}

The overall reliability of the questionnaire for the current study was found at 0.96

\section{Employee's Performance Construct}

This section defines the performance of employees working in the current organization. A five items scale was used to measure the level of employee performance after being effected by other independent variables i.e. stress and work 
overload. The questions are analyzed through a reliability tool in SPSS and the value of Cronbach's alpha is obtained 0.83 .

Table 4.3 Reliability of Employees Performance

\begin{tabular}{ll}
\hline \multicolumn{2}{c}{ CRONBACH'S ALPHA } \\
\hline EP 1 & 0.683 \\
EP 2 & 0.929 \\
EP 3 & 0.874 \\
EP 4 & 0.745 \\
EP 5 & -0.055
\end{tabular}

\section{Correlation Analysis}

Correlation analysis was used to measure the strength of a relationship between two variables under study. It predicts the change in one variable due to the change in the value of the other variable. Its value expressed on a scale ranges from -1.0 to +1.0 and the strength of the relationship at both extremes provides the best predictions. Pearson correlation method was used to measure the correlation between the hypothesized variables which includes stress, work overload and employee performance. In the first hypothesis, Stress influence was identified on the employee's performance. The following results from correlating both variables. In order to report the relationship between the dependent variable (employee's performance) and independent variables (stress and work overload), Pearson Correlation analysis is performed. The results of correlation analysis are as under.

\begin{tabular}{lllll} 
& \multicolumn{2}{c}{ Table 4.10 } & \multicolumn{2}{c}{ Correlations } \\
\hline & & ST & WOL & EsP \\
\hline ST & Pearson Correlation & 1 & $.971^{* *}$ & $-.905^{* *}$ \\
& Sig. (2-tailed) & & .000 & .000 \\
& N & 281 & 281 & 281 \\
\multirow{2}{*}{ WOL } & Pearson Correlation & $.971^{* *}$ & 1 & $-.910^{* *}$ \\
& Sig. (2-tailed) & .000 & & .000 \\
& N & 281 & 281 & 281 \\
EsP & Pearson Correlation & $-.905^{* *}$ & $-.910^{* *}$ & 1 \\
& Sig. (2-tailed) & .000 & .000 & \\
& N & 281 & 281 & 281 \\
\hline
\end{tabular}

**. Correlation is significant at the 0.01 level (2-tailed).

The above table shows that the correlation between the dependent variable EsP (Employee's Performance) and ST (Stress) is $(\mathrm{r}=-0.90, \mathrm{P}<0.5)$, which shows that there is a significant and negative relationship between Employee's Performance and Stress. The correlation between EsP (Employee's Performance) and WOL (Work Overload) is ( $\mathrm{r}$ $=-0.91, p<0.5)$, which shows that there is a significant and negative relationship between employee performance and work overload.

\section{Regression Analysis}

It shows the dependency of one variable on another variable. In regression analysis on the basis of one variable i-e independent variable, we explain the other variable i-e dependent variable. In regression analysis, if the significance level is less than 0.05 i-e $p<0.05$ then the independent variable has a significant relationship with the dependent variable.

Regression analysis is applied to test the dependency of the dependent variable on independent variables and the following results are obtained:

\begin{tabular}{|c|c|c|c|c|c|}
\hline \multirow[t]{2}{*}{$\mathrm{T} \quad$ Table 4.11} & \multicolumn{5}{|c|}{ Employee's performance } \\
\hline & $\mathrm{B}$ & $\mathrm{R} 2$ & $\mathrm{t}$ & $\mathrm{F}$ & Sig \\
\hline St Stress & -0.905 & 0.820 & -35.613 & 1268.320 & 0.00 \\
\hline Work overload & -0.910 & 0.910 & -36.549 & 1335.838 & 0.00 \\
\hline
\end{tabular}

Identifying the values of $\beta, \mathrm{R} 2, \mathrm{~T}, \mathrm{~F}$ and the level of significance

$\beta$ is the standardized regression coefficient which represents how much independent variable influences the dependent variable. If the beta value is positive then it will interpret that for every 1 unit increase in the independent variable, the dependent variable will move by lunit in the positive direction by the unstandardized beta coefficient. The value of $\beta$ for the current study is negative. Beta value for Stress is- 0.905 it means that each unit decrease in stress will bring a 0.905 unit increase in the dependent variable (Employee's Performance) and vice versa. For work overload, the value of $\beta$ is -0.910 which shows that each unit decrease in work overload will bring a 0.905 unit increase in employee performance and vice versa.

$\mathrm{R} 2$ is also known as the coefficient of determination. The value of $\mathrm{R} 2$ ranges from 0 to 1 . If the value of $\mathrm{R}$-square comes 0 it will indicate that the model explains none of the variability of the response data around its mean. 1 indicates that the model explains all the variability of the response data around its mean. In the current study, the value of R2 for stress was 0.820 which is near to land shows that the model explains the variability of the response data around its mean. The value of R-square for work overload was 0.910 . The levels of significance for both variables were 0.00 which is less than 0.5 .

\section{Future RESEARCH DIRECTIONS}

Other organizations should also be taken to interpret the impact of independent variables on the employee's performance. Comparisons should be made between two organizations to test the effects on employee's performance. The comparison may be taken among two universities or between two other organizations of different sectors. Private universities should be taken to check the impact of independent variable impact on employee's performance.

This study is carried out in university. In the future, the study should be carried out in another sector of the economy like the banking sector, production or any other sector with more possible population and sample size. 
More research can be carried out to analyze the effect of different variables like incentives, technology; the internal and external environment of organizations and management strategies on employee performance is needed

\section{Conclusion}

The purpose of the study was to find and analyze the association among stress, work overload and employee performance involved in an organization. Stress and work overload have effects on employee's overall productivity in a negative way which in turn hinders the achievements of organizational goals. The organization should take care of the level of satisfaction of workers if it wants to produce positive results. The more are the employees satisfied the more they will be productive and service-oriented in the achievement of organizational objectives?

In developing countries like Pakistan stress is the major and very common factor because the establishments of these countries don't consider stress to be effective in employee's performance. The problem promotes stress and work-life conflicts which demotivate employees and decrease the performance level. Different types of incentives, relaxation, motivation and encouragement can be used by the organizations to take out the employees from stress. The work overload can be reduced by making the ghost employees available for work or hire more in case of deficiency. In this way, the employees can be made satisfied which will lead to organizational success and achievement of the strategic goals. Different writers and researchers have given their arguments in this regard. All are of the opinion that work overload and stress impact on employee's performance.

Employees of five different public sector universities are analyzed for the effect of stress and work overload on their performance towards their job. All these universities were visited to obtain the responses of the employees regarding stress and work overload which they are facing through questionnaires adapted from the research of (Donald $\mathrm{A}$ Buckingham ,2004) and (Kavitha Venugobal 2017).

\section{REFERENCES}

Aguinis, H., Gottfredson, R. K., \& Culpepper, S. A. (2013). Best-practice recommendations for estimating cross-level interaction effects using multilevel modeling. Journal of Management, 39(6), 1490-1528.

Ajayi, D. S. (2018, April 11). Effect of Stress on Employee Performance and Job Satisfaction: A Case Study of Nigerian. Retrieved from https://papers.ssrn.com/sol3/

Arshadi, N., \& Damiri, H. (2013). The Relationship of Job stress with Turnover Intention and Job Performance: Moderating Role of OBESE. Procedia - Social and Behavioral Sciences, 706-710.

Baron, R. A., Franklin, R. J., \& Hmieleski, K. M. (2016). Why entrepreneurs often experience low, not high, levels of stress: The joint effects of selection and psychological capital. Journal of Management, 42(3), 742-768.
Buckingham, D. A. (2004). Associations among stress, work overload, role conflict, and self-efficacy in Maine principals (Doctoral dissertation, University of Maine).

Garton, E., \& Mankins, M. C. (2015). Engaging your employees is good, but don't stop there. Harvard Bus. Rev. Available at https://hbr. org/2015/12/engaging-your-employees-is-good-but-donot-stop-there [cited 15 March 2016]

Hudek-Knežević, J., Kalebić Maglica, B., \& Krapić, N. (2011). Personality, organizational stress, and attitudes toward work as prospective predictors of professional burnout in hospital nurses. Croatian medical journal, 52(4), 538-549.

Kavitha, V. (2017). The relationship and effect of role overload, role ambiguity, work-life balance and career development on work stress among call center executives of business process outsourcing (BPO) in Selangor (Doctoral dissertation, Universiti Utara Malaysia).

Knezevic, B., Milosevic, M., Golubic, R., Belosevic, L., Russo, A., \& Mustajbegovic, J. (2011). Work-related stress and workability among Croatian university hospital midwives. Midwifery, 27(2), 146-153.

Kvaløy, O., Nieken, P., \& Schöttner, A. (2015). Hidden benefits of reward: A field experiment on motivation and monetary incentives. European Economic Review, 76, 188-199.

Marchese, M. C., \& Muchinsky, P. M. (2003). Concept Charts for Study and Review for Muchinsky's" Psychology Applied to Work". Wadsworth/Thomson.

Prawirosentono, S. (2008). Manajemen Sumber Daya Manusia Kebijakan Kinerja Karyawan Kiat Membangun Organisasi Kompetitif Era Perdagangan Bebas Dunia. Edisi kedua. Yogyakarta: BPFE.

Schechner, R. (2014). The conservative avant-garde. In Performed Imaginaries (pp. 26-41). Routledge.

Sonnentag, S., \& Fritz, C. (2015). Recovery from job stress: The stressordetachment model as an integrative framework. Journal of Organizational Behavior, 36(S1), S72-S103

Zhang, Y., LePine, J. A., Buckman, B. R., \& Wei, F. (2014). It's not fair... or is it? The role of justice and leadership in explaining work stressor-job performance relationships. Academy of Management Journal, 57(3), 675-697. 


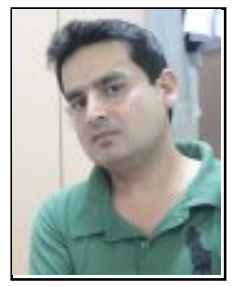

\section{Dr. Aftab Alam (PhD)}

Assistant Professor : Department of Management Sciences Abasyn University Peshawar Pakistan

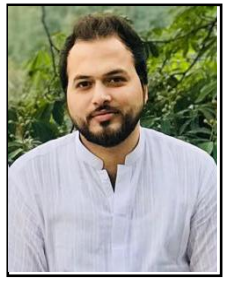

\section{Fahad Ikram Ul Haq}

MS - Scholar : Department of Management Sciences Abasyn University Peshawar Pakistan

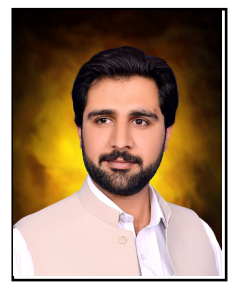

\section{Syed Sardar Ul Mulk}

MS - Scholar : Department of Management Sciences Abasyn University Peshawar Pakistan

\section{Farah Rafiq}

MS Scholar : Department of Management Sciences Abasyn University Peshawar Pakistan 